\title{
A Test of Factors Mediating the Relationship Between Unwanted Sexual Activity During Childhood and Risky Sexual Practices Among Women Enrolled in the NIMH Multisite HIV Prevention Trial
}

\section{The NIMH Multisite HIV Prevention Trial Group}

To cite this article: The NIMH Multisite HIV Prevention Trial Group (2001) A Test of Factors Mediating the Relationship Between Unwanted Sexual Activity During Childhood and Risky Sexual Practices Among Women Enrolled in the NIMH Multisite HIV Prevention Trial, Women \& Health, 33:1-2, 163-180, DOI: 10.1300/J013v33n01_10

To link to this article: https://doi.org/10.1300/J013v33n01_10

\section{曲 Published online: 21 Oct 2008.}

Submit your article to this journal ¿

\section{山ll Article views: 121}

Q View related articles $\longleftarrow$

Citing articles: 43 View citing articles $[\pi$ 


\title{
A Test of Factors Mediating the Relationship Between Unwanted Sexual Activity During Childhood and Risky Sexual Practices Among Women Enrolled in the NIMH Multisite HIV Prevention Trial
}

\author{
The NIMH Multisite HIV Prevention Trial Group
}

SUMMARY. This study examined both the direct and indirect associations between unwanted sexual activity during childhood and HIV-related sexual practices of adult women. The sample consisted of 3,346 women recruited from sexually transmitted disease (STD) clinics and health service organizations. The findings demonstrated that participants who reported unwanted sexual activity as a child (USC) were more likely than women who did not report such experience to indicate that they had problems with alcohol, used drugs, received money or drugs in exchange for sex, had unwanted sex, and used mental health services. The women reporting USC also noted a greater number of unprotected sex acts, a greater number of partners, and a greater proportion of sex acts accompanied by drugs or alcohol in the past 90 days. Mediated anal-

Funded by the National Institute of Mental Health-U10 MH49062.

Address correspondence to: Colleen DiIorio, Rollins School of Public Health, Emory University, 1518 Clifton Road, Atlanta, GA 30322 (E-mail: cdiiori@sph. emory.edu).

[Haworth co-indexing entry note]: "A Test of Factors Mediating the Relationship Between Unwanted Sexual Activity During Childhood and Risky Sexual Practices Among Women Enrolled in the NIMH Multisite HIV Prevention Trial.” The NIMH Multisite HIV Prevention Trial Group. Co-published simultaneously in Women \& Health (The Haworth Medical Press, an imprint of The Haworth Press, Inc.) Vol. 33, No. 1/2, 2001, pp. 163-180; and: Women's Work, Health and Quality of Life (ed: Afaf Ibrahim Meleis) The Haworth Medical Press, an imprint of The Haworth Press, Inc., 2001, pp. 163-180. Single or multiple copies of this article are available for a fee from The Haworth Document Delivery Service [1-800-342-9678, 9:00 a.m. - 5:00 p.m. (EST). E-mail address: getinfo@haworthpressinc.com].

(C) 2001 by The Haworth Press, Inc. All rights reserved. 
yses showed that drug use, exchange of sex for money/drugs, unwanted sex, and to a lesser extent, problems with alcohol mediated the relationship between USC and unprotected sex acts, number of partners, and sex under the influence of drugs and alcohol. These findings suggest that participation in non-sexual risky behaviors among women who report USC may be a bridge to participation in sexual behaviors that increase their risk of HIV infection. [Article copies available for a fee from The Haworth Document Delivery Service: 1-800-342-9678. E-mail address: $<$ getinfo@ haworthpressinc.com> Website: <http://www.HaworthPress.com> (C) 2001 by The Haworth Press, Inc. All rights reserved.]

KEYWORDS. Childhood sexual abuse, HIV, AIDS, women's health

In recent years, the greatest rate of increase in AIDS cases has occurred among women (Centers for Disease Control and Prevention (CDC), 1999). From July 1998 through June 1999, 23\% of new AIDS cases were among women, and women accounted for $16 \%$ of all reported AIDS cases compared to 7\% in 1985 (CDC, 1999, 1997). Moreover, women accounted for $32 \%$ of all new HIV infections among adults and $49 \%$ of all new infections among women ages 13-24 years. Although for $32 \%$ of women with AIDS, a risk factor was not identified, $40 \%$ of women diagnosed with AIDS reported sexual contact with men, and $28 \%$ reported injection drug use as their most likely route of infection (CDC, 1999). To control the rate of infections among women, it is important to understand factors that increase a woman's chance of contracting HIV, the virus responsible for AIDS.

For some time, researchers have acknowledged the association between childhood sexual abuse and subsequent HIV-related sexual behavior (Allers \& Benjack, 1991; Wyatt, 1988; Zierler et al., 1991). For example, women who experienced sexual abuse as children are more likely than women who experienced no sexual abuse to have sex with casual partners, brief sexual relationships, and multiple partners (Thompson, Potter, Sanderson, \& Maibach, 1997; Miller, 1997; Wyatt, 1988; Zierler et al., 1991). In addition, women sexually abused in childhood are more likely to use drugs and alcohol and to use mental health services, trade sex for money or drugs, and to engage in unwanted sex (Felitti et al., 1998; Gilbert, El-Bassel, Schilling, \& Friedman, 1997; Simons \& Whitbeck, 1991; Springs \& Friedrich, 1992)-behaviors associated with risky sexual practices (Johnsen, 1996; MacDonald, Zanna, \& 
Fong, 1996; Meilman, 1993) and HIV infection (Astemborski, Vlahov, Warren, Solomon et al., 1994).

The present study was undertaken to examine the association between unwanted sexual activity as a child (USC) and HIV-related sexual practices. We were also interested in understanding the association between USC and risky practices such as alcohol and drug use and how these risky practices might increase a woman's chance of engaging in risky sexual practices. The findings from studies on long-term consequences of childhood sexual abuse suggest that certain risky practices might serve to increase a woman's chance of engaging in risky sexual practices. Briere (1992), for example, found that women who experience sexual abuse as children are more likely to use drugs and alcohol during sexual encounters. He suggests that women might use drugs and alcohol during sex to avoid abuse-related memories. Other researchers have shown that alcohol and drug use are likely to interfere with sexual decision-making and negotiation for condom use (Clapper \& Lipsitt, 1991; MacDonald et al., 1996; Meilman, 1993), thereby increasing the likelihood of unprotected sex and sex with casual partners. Trading sex for money or drugs, by its very nature, is likely to involve sexual encounters that increase one's risk of contracting HIV (Astemborski et al., 1994). Johnsen (1996) has found that sexually abused women are more likely to engage in risky sexual practices if they have a history of unwanted sex as an adult. Because women abused as children often suffer long-term mental health consequences of this early experience, it is important to explore how mental health relates to HIV-related risk behaviors as well.

A better understanding of the relationship between unwanted sexual experiences during childhood and risky sexual practices can lead to the development of more effective HIV prevention interventions. One way to enhance our understanding of this association is to examine factors that may potentiate this relationship. Given the empirical evidence that alcohol use, drug use, trading sex for money or drugs, unwanted sex, and mental health problems might function as mediators of the relationship between childhood sexual abuse and HIV-related sexual practices, further investigation is warranted. Thus, in the present study, we examined both direct and indirect influences of USC on risky sexual practices. More specifically, we hypothesized that women who experience USC as compared to those without this experience would be more likely to indicate that they had unprotected sex, had more sexual partners, and had sex under the influence of alcohol and drugs. We further hypothesized that women who experience USC would report using drugs, having 
problems with alcohol, exchanging sex for money or drugs, unwanted sex as an adult, and using mental health services, and that participation in these behaviors would increase their risk of engaging in high risk sexual practices. Given that findings of previous studies on childhood sexual abuse among women have been based predominantly on bivariate correlations, the present study in which mediation analysis was used could help clarify the extent to which participation in behaviors such as alcohol and drug use leads to involvement in HIV-related sexual practices.

\section{METHOD}

\section{Procedures}

This study was part of a large multisite trial to test the efficacy of an HIV intervention in reducing risky sexual practices among adults at high risk for contracting HIV (see NIMH Multisite HIV Prevention Trial, 1997, for a more complete description of the study). The NIMH Multisite HIV Prevention Trial was a Cooperative Agreement between the National Institute of Mental Health and seven research sites located in the following metropolitan areas: Atlanta, Georgia; Baltimore, Maryland; Milwaukee, Wisconsin; Los Angeles, California; and New York City. We recruited and screened men and women for participation in a randomized controlled clinical trial designed to reduce HIV risk through modification of sexual behavior. Eligibility criteria included unprotected vaginal and/or anal intercourse and high-risk sexual partners in the past 90 days. We recruited individuals through sexually transmitted disease clinics and other health services organizations. A total of 6,022 men and women meeting the inclusion criteria completed a baseline interview. Prior to beginning the interview, the interviewer explained the purpose of the study, the benefits and risks for participation, and the procedures used for protection of confidentiality. After written informed consent was obtained, participants completed a face-to-face interview administered by trained interviewers. Participants received between $\$ 10$ and $\$ 20$ for their time. The analyses for this study include data from the 3,346 women who completed the baseline assessment.

\section{Measures}

Unwanted sexual activity during childhood (USC). The study assessed unwanted sexual activity during childhood with a single ques- 
tion: "Before you were 13, did you ever have unwanted/uninvited sexual activity with someone 5 or more years older?"

Alcohol use problems. Problems related to alcohol use were assessed using the CAGE, a 4-item screening instrument (Mayfield, McLeod, \& Hall, 1974). Research has shown that scores of 2 or more are sensitive and specific for identifying individuals with chronic alcohol use problems (King, 1986).

Drug use. To assess drug use, interviewers asked participants if, during the past 90 days, they had used any of the following: marijuana or hashish, sedatives or barbiturates, tranquilizers, PCP, hallucinogens, nitrites or poppers, crack or free base, cocaine or heroin (either sniffed or snorted), inhalants, amphetamines, or ecstasy. Interviewers then asked participants whether they had injected any drug in the past 90 days. For this analysis, we classified any person reporting "yes" to either question as using drugs. Previous research has shown that cocaine, heroin, and injection drugs are associated with sexual risk behavior (Schilling, El-Bassel, Gilbert, \& Schinke, 1991). For this reason, we further classified drug users by type of drug used. Group one consisted of participants who reported use of cocaine or heroin in any form or injection of drugs. The second group consisted of participants who reported use of any other drug.

Sex for money or drugs. The interviewers asked participants if during the past 90 days they had sex with someone to get money or drugs.

Unwanted sexual activity. To assess unwanted sexual activity, interviewers asked participants if during the past 90 days they had unwanted sexual activity with someone because they were threatened or physically forced to have sex.

Mental health services. Interviewers asked participants if within the past 90 days they had ever stayed overnight at a hospital for treatment of mental or emotional problems, family or personal problems, or problems with nerves as well as if they had ever seen a counselor or were currently taking medication for mental or emotional problems or nerves. We coded any affirmative answer as a positive response.

Sexual risk behaviors. We assessed four different sexual risk practices: number of unprotected sex acts, proportion of sex acts without a condom, number of partners, and proportion of sex acts accompanied by drugs or alcohol. To compute these variables, interviewers asked participants to report the number of partners with whom they had sex with during the past 90 days. For each partner, data were collected on number of sex acts, number of times participants used a condom, and number of times they used alcohol or drugs. Interviewers asked partici- 
pants with more than five partners to estimate the number of sex acts and the number of times they used a condom and alcohol and/or drugs with these additional partners.

Demographics. The study used standard items to assess participants' gender, race/ethnic background, age $(<25,25-35,>35)$, living situation (living with a partner; not living with a partner), education (high school degree or more; less than a high school degree), study population (STD clinic or health services organization), and study site (the seven participating research sites).

\section{Participants}

The 3,346 female participants ranged in age from 18 to 65 with a mean age of 30 years $(S D=8.0)$. Overall, $62.7 \%$ percent of female participants were Black, non-Hispanic, and $27.5 \%$ percent were Hispanic (Table 1). Slightly more than half (53\%) of the respondents had a high school degree, and $38.9 \%$ were living with a sex partner. Thirty-eight percent of participants reported unwanted/uninvited sexual activity before they were 13 years of age. Women who reported USC did not differ significantly from peers who did not report USC with respect to age, education, and living status. However, a smaller proportion of women reporting USC were of Hispanic background, and significantly more women reporting USC were recruited from the STD clinics than from health service organizations.

\section{RESULTS}

Using SAS Version 6.12 (1997), we first calculated frequencies and percentages for all study variables and used chi-square analyses to determine if differences existed between participants who reported USC and those who did not report this experience. As shown in Table 1, for the total sample of women, $29.5 \%$ reported alcohol problems; $22.9 \%$ reported cocaine, heroin, or injection drug use; and $21.1 \%$ reported use of other drugs, primarily marijuana. Participants reporting USC were more likely than respondents not reporting USC to use alcohol (37\% vs. $24.8 \%$ ) and drugs (50.4\% vs. $40 \%$ ). The exchange of sex for money/ drugs was higher among participants reporting USC (17.8\%) than their counterparts $(8.8 \%)$, and a greater percent of participants indicating USC as compared to those without a history of USC reported unwanted sex in the past 90 days (11.2\% vs. 5.4\%). Use of mental health services 
TABLE 1. Frequencies and Percentages for Demographic Characteristics and Mediating Variables for the Total Sample and for Participants With and Without USC

\begin{tabular}{|c|c|c|c|c|c|c|c|}
\hline \multirow[t]{2}{*}{ Variable } & \multicolumn{2}{|c|}{ Total } & \multicolumn{2}{|c|}{ Non-USC } & \multicolumn{2}{|c|}{ USC } & \multirow[b]{2}{*}{$\mathrm{p} \mathrm{Value}^{1}$} \\
\hline & Frequency & Percent & Frequency & Percent & Frequency & Percent & \\
\hline \multicolumn{8}{|l|}{ Age } \\
\hline$<25$ & 1130 & 33.9 & 681 & 33.2 & 449 & 35.0 & 0.5 \\
\hline $25-35$ & 1319 & 39.5 & 826 & 40.2 & 493 & 38.4 & \\
\hline$>35$ & 887 & 26.6 & 546 & 26.6 & 341 & 26.6 & \\
\hline \multicolumn{8}{|l|}{ Race } \\
\hline Hispanic non-Black & 741 & 22.3 & 505 & 24.7 & 236 & 18.5 & 0.001 \\
\hline Hispanic, Black & 171 & 5.2 & 106 & 5.2 & 65 & 5.1 & \\
\hline Non-Hispanic, Non-Black & 328 & 9.9 & 177 & 8.7 & 151 & 11.8 & \\
\hline Black, Non-Hispanic & 2081 & 62.7 & 1255 & 61.4 & 826 & 64.6 & \\
\hline \multicolumn{8}{|l|}{ Education } \\
\hline High school degree & 1767 & 53.0 & 1071 & 52.2 & 696 & 54.3 & 0.2 \\
\hline No high school degree & 1567 & 47.0 & 981 & 47.8 & 586 & 45.7 & \\
\hline \multicolumn{8}{|l|}{ Living arrangement } \\
\hline Living with partner & 1298 & 38.9 & 789 & 38.4 & 509 & 39.7 & 0.5 \\
\hline Not living with partner & 2038 & 61.1 & 1264 & 61.6 & 774 & 60.3 & \\
\hline Alcohol problems & 979 & 29.5 & 506 & 24.8 & 473 & 37.0 & 0.001 \\
\hline Drug use & 1469 & 44.0 & 822 & 40.0 & 647 & 50.4 & \\
\hline Cocaine/heroin/injection & 764 & 22.9 & 418 & 20.4 & 346 & 27.0 & 0.001 \\
\hline Other & 705 & 21.1 & 404 & 19.7 & 301 & 23.5 & \\
\hline Traded sex for money/drugs & 409 & 12.3 & 181 & 8.8 & 228 & 17.8 & 0.001 \\
\hline Unwanted sex & 254 & 7.6 & 111 & 5.4 & 143 & 11.2 & 0.001 \\
\hline Mental health services & 429 & 12.9 & 192 & 9.4 & 237 & 18.5 & 0.001 \\
\hline
\end{tabular}

${ }^{1}$ By Chi-square test: Testing USC versus non-USC percentages.

was reported by $18.5 \%$ of participants reporting USC and $9.4 \%$ of participants reporting no USC. In each case, the percent of participants with a history of USC and reporting these behaviors was significantly higher than the percent of participants without this history.

With respect to behaviors that place women at risk for contraction of $\mathrm{HIV}$, the average number of unprotected sex acts during the past 90 days was 27.1 for participants reporting USC and 22.9 for participants without a history of USC $(\mathrm{p}<.0001)$ (Table 2$)$. The average proportion of sex acts in which participants failed to use condoms was $80 \%$, equivalent for both participants reporting USC and those not reporting this experience. The average number of partners was 3.2 for participants reporting USC and 2.6 for participants who did not indicate USC. Finally, the proportion of intercourse acts accompanied by drugs or alcohol was 
TABLE 2. Means and Standard Deviations for Outcome Variables for the Total Sample and for Participants With and Without USC

\begin{tabular}{lrrrrrrr}
\hline Outcomes & \multicolumn{2}{c}{ Total } & \multicolumn{2}{c}{ Non-USC } & \multicolumn{2}{c}{ USC } \\
\hline & Mean & SD & Mean & SD & Mean & SD & p value \\
Unprotected acts & 24.5 & 42.2 & 22.9 & 41.9 & 27.1 & 42.7 & 0.0001 \\
Number of partners & 2.8 & 11.1 & 2.6 & 12.4 & 3.2 & 8.6 & 0.0001 \\
Proportion of acts with drugs or alcohol & .23 & .33 & .20 & .31 & .28 & .35 & 0.0001 \\
Proportion of non-condom use & .80 & .27 & .80 & .28 & .80 & .26 & 0.1 \\
\hline
\end{tabular}

${ }^{1}$ By the Wilcoxoan test

$28 \%$ for participants with USC and $20 \%$ for participants not reporting USC.

\section{Mediation Analysis}

To determine whether the association between USC and high risk sexual behavior was mediated by the hypothesized variables (alcohol problems, drug use, sex for money/drugs, unwanted sex, and use of mental health services), we constructed regression models to test for mediation. According to Baron and Kenny (1986), for mediation to exist (1) the independent variable must be significantly related to the outcome variable, (2) the independent variable must be significantly related to the mediator variable, and (3) when all three variables are examined together, the previously significant relationship between the independent and outcome variables is no longer statistically significant or the significance is greatly reduced.

In the first stage of our mediation analysis, we examined the association of USC (the independent variable) and each behavioral outcomefrequency of unprotected acts, proportion of acts without using a condom, number of partners, and proportion of acts with drugs/alcohol. To determine whether USC was significantly related to each behavioral outcome, we regressed each outcome onto a dummy variable, USC, that was coded 0 for participants not reporting USC and 1 for those reporting USC. The regression models also included the background variables of race/ethnicity, age, education, study population, and study site entered simultaneously with USC into the models. For frequency of unprotected acts and number of partners, models were fit to the square root of these outcomes in order to help normalize their distributions. 
The results showed that USC was a significant predictor of the frequency of unprotected acts, number of partners, and proportion of acts with drugs/alcohol. However, it was not a significant predictor of the proportion of sex acts that occurred without use of a condom (Table 3 ). The parameter estimates, or unstandardized regression coefficients (Beta), calculated using SAS for USC were .40 ( $\mathrm{p}<0.001)$ for unprotected sexual acts, $.02(\mathrm{p}=0.1)$ for proportion of sex acts without condoms, .13 ( $\mathrm{p}<0.001)$ for number of partners, and $.07(\mathrm{p}<0.001)$ for proportion of acts with drugs/alcohol. Because the association between USC and proportion of sex acts without condoms was not significant at this first step, we dropped this variable from further analysis.

In the second step, the study examined the relationship between USC and each mediator variable. We conducted a series of logistic regression models using the mediator variables as separate outcome variables. Independent variables included USC, race/ethnicity, age, education, study population, and study site. USC was significantly related to each of the mediator variables. That is, participants who reported USC were more likely to report alcohol problems (OR: $1.76 ; 95 \%$ CI: $1.51,2.06$ ), to have used drugs (OR: 1.45; 95\% CI: 1.26, 1.67), to have engaged in sex for money/drugs (OR: 2.28; 95\% CI: 1.83, 2.83), to have had unwanted sex (OR: $2.12 ; 95 \%$ CI: 1.63, 2.75), and to have used mental health services (OR: 2.24; 95\% CI: 1.81, 2.77).

TABLE 3. Beta Estimates for Behavioral Outcomes With and Without Mediators of Unwanted Sexual Activity During Childhood

\begin{tabular}{lcc|cccc}
\hline Dependent Variables & \multicolumn{3}{c}{ USC Without Mediators } & \multicolumn{5}{c}{ USC With Mediators } \\
\hline Behavioral Outcomes & $\begin{array}{c}\text { Beta Estimate } \\
(\text { s.e. })^{1}\end{array}$ & p value & $\begin{array}{c}\text { Beta Estimate } \\
(\mathrm{s} . \mathrm{e} .)^{2}\end{array}$ & $\mathrm{p}$ value & $\%$ change ${ }^{3}$ & $\mathrm{p}$ value \\
Unprotected acts & $.40(.10)$ & 0.0001 & $.26(.10)$ & 0.01 & 35 & 0.3 \\
$\begin{array}{l}\text { Proportion non-condom } \\
\text { use }\end{array}$ & $.02(.01)$ & 0.1 & ---- & ---- & --- & ---- \\
$\begin{array}{l}\text { Number of partners } \\
\begin{array}{l}\text { Proportion sex with } \\
\text { drugs/alcohol }\end{array}\end{array}$ & $.13(.03)$ & 0.0001 & $.015(.03)$ & 0.6 & 88 & 0.006 \\
\hline
\end{tabular}

1 Parameter estimates and standard errors for the USC indicator variable from models fit to each outcome. Each model included effects for age, race/ethnicity, education (high school degree or not), location of health services, and site in addition to the USC indicator. P-value is for a test of whether the parameter is significant.

2 Parameter estimates, standard errors, and tests for the USC indicator from models which in addition to the variables included in the without mediators models included the mediator effects for drug use, alcohol use, sex for money or drugs, unwanted sex, and use of mental health services.

3 Proportion of the USC effect on outcomes explained by the mediators. \% change $=[1-(\beta$ with $/ \beta$ without $)]$. $\mathrm{P}$-value for a test of whether this change is significant. 
The purpose of the third step in the analysis was to determine whether the association between USC and the outcome variables-frequency of unprotected acts, number of partners, and proportion of acts under the influence of drugs/alcohol-remained significant after inclusion of the mediator variables. We constructed regression models with USC and mediators as independent variables; and as noted above, all models included the effects of the background variables-race/ethnicity, age, education, study population, and study site.

The results showed that for frequency of unprotected acts, number of partners, and proportion of acts with drugs/alcohol, USC was a significant predictor before the addition of the mediator variables. The significance for frequency of unprotected acts and proportion of acts with drugs/alcohol was reduced, and that for number of partners became nonsignificant after we added the mediators to the models.

For unprotected acts, the parameter estimate for USC was reduced from $.40(\mathrm{p}<0.0001)$ to $.26(\mathrm{p}<0.01)$ with the addition of the mediators. Mediators explained 35\% of the USC effect $(\mathrm{p}=0.3)$ for a test of whether the reduction was significant (Freedman, Graubard, \& Schatzkin, 1992). The mediators that remained significant after inclusion in the model were cocaine/heroin or injection drug use $(b=.74, p<0.001)$, other drug use $(\mathrm{b}=.31, \mathrm{p}<0.05)$, and sex for money/drugs $(\mathrm{b}=.81, \mathrm{p}<$ $0.001)$. In the final model, significant associations were also noted for race, age, and study site.

For number of partners, the parameter estimate for USC was reduced from $.13(\mathrm{p}<0.001)$ to $.015(\mathrm{p}=0.6)$ with the addition of the mediators, which represents an approximately $88 \%$ reduction in the USC effect (p $<0.006$ for a test of significance of reduction). The mediators that remained significant after inclusion in the model were cocaine/heroin or injection drug use $(b=.28, \mathrm{p}<0.001)$, other drug use $(\mathrm{b}=.11, \mathrm{p}<0.01)$, sex for money/drugs $(b=1.0, p<0.001)$, and unwanted $\operatorname{sex}(b=.30, p<$ 0.001 ). In the final model, significant associations were also noted for race, age, study population, and study site.

Adding the mediators to the model based on the outcome of proportion of acts with drugs/alcohol reduced the parameter estimate for USC from .07 ( $\mathrm{p}<0.001)$ to .03 ( $\mathrm{p}<0.002)$, a reduction of approximately $57 \%(\mathrm{p}=0.01)$. The mediators that remained significant were alcohol problems $(b=.09, p<0.001)$, cocaine/heroin or injection drug use $(b=$ $.23, \mathrm{p}<0.001)$, other drug use $(\mathrm{b}=.17, \mathrm{p}<0.001)$, sex for money/drugs $(b=0.1, p<0.001)$, and unwanted sex $(b=.05, p<0.05)$. In the final model, significant associations were also noted for age. Thus, for each 
behavioral outcome, the mediators typically explained some but not all of the effects of USC.

\section{DISCUSSION}

The results of this study are consistent with previous studies that find that women who experience sexual abuse as children tend to engage in unhealthy behaviors that might place them at risk for contracting HIV (Allers \& Benjack, 1991; Astemborski et al., 1994; Wyatt, 1988; Zierler et al., 1991). Compared to those who experience no sexual abuse, women reporting USC note more problems with alcohol and drugs use. The proportion of participants with USC who reported involvement in sex for money/drugs, unwanted sex, and use of mental health services is twice that of participants without USC. Moreover, participants reporting USC are more likely to report risky sexual practices including a greater number of sexual acts not protected by a condom, more partners, and a larger proportion of sexual acts accompanied by drugs and/or alcohol.

Analysis testing the indirect effects of USC on risky sexual practices suggests that drug use is a link between USC and HIV-related sexual practices. Thus, having experienced unwanted sexual activity as a child appears to increase a woman's risk of using drugs, and using drugs appears to be associated with unprotected sexual acts, number of partners, and acts accompanied by alcohol or drugs. The role of drug use as a mediator between USC and risky sexual practices may best be understood from the work of previous investigators, who have found a similar association between childhood sexual abuse and drug use (Felitti et al., 1998; Springs \& Friedrich, 1992). In explaining this relationship, researchers agree that women turn to drug use to cope with the residual effects of childhood sexual abuse (Felitti et al., 1998; Polusny \& Follette, 1995). The relationship between drug use and risky sexual practices has at least two possible explanations. The first one is that drugs interfere with cognitive capacities, thereby compromising decision-making and reducing sexual inhibitions leading to a greater likelihood of making poor choices with respect to sexual risk-taking. This interpretation is consistent with findings that decision-making ability is inversely associated with sexual risk behavior among women who use injection drugs (Joe, Knezek, Watson, \& Simpson, 1991).

An alternative explanation for the association between drug use and $\mathrm{HIV}$ risk practices involves the social context in which drugs use oc- 
curs. According to this view, using drugs may place women in social settings and economic circumstances associated with sexual risk-taking (El-Bassel et al., 1997). That is, the illicit nature of the drugs requires users to participate in elaborate social networks to secure drugs and basic living needs, and this environment may expose women to a variety of risks, including unprotected sex.

The finding that alcohol use fails to function as a mediator for unprotected sex or number of partners strengthens this second explanation. Our findings show that women reporting unwanted sexual activity as children are more likely to drink alcohol, suggesting that, like drugs, alcohol may serve as a coping strategy for dealing with the residual effects of childhood sexual abuse. However, alcohol use is neither a strong predictor of unprotected sex acts nor number of partners. Crosssectional studies, particularly among adolescents and young adults, suggest that alcohol plays a primary role in risky sexual situations (Norris \& Hughes, 1996). One explanation for this relationship is that alcohol diminishes decision-making abilities, leading to poor choices regarding HIV protective practices (MacDonald et al., 1996). Yet, researchers sometimes fail to replicate these results among adult women in event-based studies (Leigh \& Stall, 1993). To address this lack of an association between alcohol use and risky sexual practices, Leigh and Stall (1993) propose that other variables be considered. Our findings suggest that perhaps the social context in which drinking occurs rather than intrapersonal decision-making abilities may play a primary role in determining whether women who drink will use HIV protective practices. The social context of alcohol use is likely to be different from the social context of drug use, and this difference can help explain the divergent results in the mediation models of alcohol and drug use. One obvious observation is that alcohol, a legal and easily obtained substance, does not require the individual to participate in a risky social network such as that associated with the procurement of illicit drugs. Further work is necessary to understand how the social context of alcohol and drug use differ, and how these social environments work to support or inhibit HIV-related sexual practices.

A second factor that links USC and HIV-related sexual practices is trading sex for money/drugs. Women reporting USC seem more likely than others to exchange sex for money/drugs, and those who are involved in trading sex report a greater number of unprotected sex acts, partners, and sexual acts accompanied by alcohol/drugs. Other researchers have observed that women sexually abused as children are more likely than others to be involved in sex trade (Simons \& Whitbeck, 
1991). One explanation for this association is that women have unresolved feelings regarding abuse that are somehow acted out through sexual promiscuity (Polusny \& Follette, 1995). The association between exchanging sex for money/drugs and number of partners may be self-explanatory as trading sex is likely to lead to both a greater number of sex acts and a greater number of partners. However, in this study, we did not collect information about the length of time women were involved in trading sex, the type of practice, and other information including psychosocial factors. These might be useful in understanding why women who appear to be at a greater risk for contracting HIV because of multiple partners and acts fail to use precautions. Further research is necessary to understand this relationship.

A third factor important in the relationship between USC and risky sexual practices is unwanted sex. Women reporting USC are more likely to note an episode of unwanted sex in the past 90 days, and these latter women report a greater number of partners and a greater proportion of sex acts under the influence of drugs/alcohol. Our findings parallel those of Johnsen (1996) who found that revictimization among sexually abused women was the most important factor associated with risky sexual practices. Her findings suggested that feelings of powerlessness in sexual situations underlie this association. Research addressing the issue of power in sexual relationships is increasing and this research could lead to a better understanding of the power dynamics of adult interpersonal relationships, that make women vulnerable to unwanted sexual encounters (Harlow, Quina, Morokoff, Rose, \& Grimley, 1993; Soet, DiIorio, \& Dudley, 1998). These dynamics may play a role in the greater propensity for choosing multiple partners and sex under the influence of substances reported by survivors of childhood sexual abuse and should be explored in future studies.

The only proposed variable that did not function as a mediator in this study was mental health services. The broad measure of mental health encompasses any number of reasons for seeking emotional assistance, and thus, it may have masked important relationships. Measures of psychological characteristics such as depression and self-esteem may be more useful in the endeavor to explore factors mediating the relationship between USC and HIV-related sexual behavior.

In addition to the proposed mediators assessed in this study, we found that some of the background variables were significantly associated with the behavioral outcomes. Participants who reported that they were not Black were more likely than those who reported that they were Black to have unprotected sexual acts. This relationship became more 
significant with the addition of the mediators. Non-Blacks in this sample were less likely to sell sex, so it is possible that they perceived less need to use condoms. Participants who described themselves as nonBlack Hispanic reported fewer sexual partners and fewer sexual acts under the influence of alcohol and drugs. These relationships were not significant in the final models, perhaps due to the fact that non-Black Hispanics also reported less selling of sex, less drug use, and fewer alcohol problems than Black participants.

We did not find a relationship between USC and proportion of condom use-the fourth outcome variable examined in this study. We measured the proportion of condom use in such a manner that it may have obscured important differences in risky behaviors among participants. For example, in the analysis, we treated the case of a woman who reported 50 sexual encounters, with 25 of them protected by a condom, in the same manner as we treated a women who reported 2 sexual encounters with 1 protected by a condom. Given our experience with the variable in the present analysis, researchers are cautioned to consider the general weakness of this variable in assessing condom use.

A limitation of the study is that it was conducted using a sample of women who reported at least one HIV risk behavior within the previous 90 days. The relationship among variables and the interpretation of the findings may differ for a more heterogeneous sample of women or for women who are at moderate or low risk for exposure to HIV. Likewise the racial and ethnic background of the participants limits the generalization of the findings to a small group of women. The study is an attempt to move beyond simple associations in understanding the impact of USC on risky sexual practices, but we acknowledge it is only a beginning step in explaining the complex relationships herein. Further work is needed to understand the psychological and social processes by which women reporting USC engage in behaviors such as alcohol and drug use, and sex for money/drugs, which appear to further increase their risk of practicing sexual behaviors that may expose them to HIV.

The findings of this study suggest that some of the increased HIV risk observed in women who report USC is directly related to that abuse history. Yet, some of the effect of USC is mediated through participation in behaviors such as drug use and exchanging sex for money/drugs. Our results indicate that the social context in which these behaviors occur may be an important factor that deserves more attention from researchers. Intervention developers must recognize that some women with a history of USC engage in a set of complex behaviors beyond those directly related to HIV risk. These behaviors appear to arise from, and be 
reinforced by, a social environment that also merits concentrated study. Interventions targeting these circumstances and behaviors may benefit from added attention to women's abuse histories in developing HIV interventions. Additionally, women may be more vulnerable to relapse into unsafe sexual behaviors even after participating in an intervention, if these circumstances are not addressed.

\section{AUTHOR NOTE}

Research Steering Committee (Site Principal Investigators and NIMH Staff Collaborator)*: David D. Celentano, ScD (Johns Hopkins University), Colleen Dilorio, PhD (Emory University), Tyler Hartwell, $\mathrm{PhD}$ (Research Triangle Institute), Jeffrey Kelly, PhD (Medical College of Wisconsin), Raul Magana, PhD, (formerly at University of California, Irvine), Edward Maibach, PhD (formerly PI at Emory University), Ann O'Leary, PhD (Rutgers University), Willo Pequegnat, PhD (National Institute of Mental Health), Mary Jane Rotheram-Borus, PhD (University of California, Los Angeles) Robert Schilling, PhD (Columbia University).

Collaborating Scientists/Co-Principal Investigators*: Jaime Amsel, $\mathrm{PhD}$ (formerly at the University of California, Irvine), Andre Ivanoff, PhD (Columbia University), Nabila El-Bassel, DSW (Columbia University), Joao B. Ferreira-Pinto, $\mathrm{PhD}$ (formerly at University of California, Irvine), John Barton Jemmott, III, PhD (Princeton University), Loretta Sweet Jemmott, PhD, RN, FAAN (University of Pennsylvania), Rebecca Martin, PhD (Johns Hopkins University), Debra Murphy, $\mathrm{PhD}$, (University of California, Los Angeles), Marcella Raffaelli, PhD (formerly at Rutgers University), Anne M. Rompalo, MD (Johns Hopkins University), William Schlenger, PhD (Research Triangle Institute), Kathleen Sikkema, PhD (Medical College of Wisconsin), Anton Somlai, EdD (Medical College of Wisconsin).

Site Managers*: Kevin Alford (Johns Hopkins University), Kristin Hackl, MSW (Medical College of Wisconsin), Michelle Parra (University of California, Los Angeles), Jennifer Sharpe-Potter, MPH (Emory University), Susan Witte, MSW (Columbia University).

Data Coordinating Center*: Nellie Hansen, MS, Deborah McFadden, MBA, Rebecca Perritt, MS, W. Kenneth Poole, PhD (Research Triangle Institute).

Core Laboratory*: Charlotte Gaydos, DrPH (Johns Hopkins School of Medicine), Thomas C. Quinn, MD (Johns Hopkins School of Medicine). 
The authors gratefully and sincerely acknowledge the following individuals and their staffs for their generous support of The NIMH Multisite HIV Prevention Trial:

Research Support Office*: Leonard Mitnick, PhD, Sherry Roberts, Ellen Stover, PhD (National Institute of Mental Health).

Data Safety and Monitoring Board*: Alan S. Bellack, PhD (University of Maryland), Thomas Coates, $\mathrm{PhD}$, Chair (University of California at San Francisco), William D. Crano, PhD (University of Arizona), David Francis, PhD (University of Houston), Sylvan B. Green, MD (National Cancer Institute), Karla Moras, PhD (University of Pennsylvania).

* All names in alphabetical order

Funded by the National Institute of Mental Health-U10 MH49062. Human subjects approval: The study was approved by the Institutional Review Board of each of the seven research sites. All participants volunteered for participation in the study. They were given information about the study that included risks and benefits and study procedures. Participants were required to sign an informed consent form prior to participation.

\section{REFERENCES}

Allers, C. T., \& Benjack, K. J. (1991). Connections between childhood abuse and HIV infection. Journal of Counseling \& Development, 70, 309-313.

Astemborski, J., Vlahov, D., Warren, D., Solomon, L., \& Nelson, K. E. (1994). The trading of sex for drugs or money and HIV seropositivity among female intravenous drug users. American Journal of Public Health, 84, 382-386.

Baron, R. M., \& Kenny, D. A. (1986). The moderator-mediator variable distinction in social psychological research: Conceptual, strategic, and statistical considerations. Journal of Personality and Social Psychology, 51, 1173-1182.

Briere, J. N. (1992). Child abuse trauma: Theory and treatment of the lasting effects. Newbury Park, CA: Sage Publications, Inc. 203 pp.

Centers for Disease Control and Prevention. (1999). HIV/AIDS Surveillance Report, 11(2), (1-41).

Centers for Disease Control and Prevention (1997). HIV/AIDS Surveillance Report, 9(1), (1-33).

Clapper, R. L., \& Lipsitt, L. P. (1991). A retrospective study of risk-taking and alcohol-mediated unprotected intercourse. Journal of Substance Abuse, 3(1), 91-96.

El-Bassel, N., Schilling, R. F., Irwin, K. L., Faruque, S., Gilbert, L., Von Bargen, J., Serrano, Y., \& Edlin, B. R. (1997). Sex trading and psychological distress among women recruited from the streets of Harlem. American Journal of Public Health, 87(1), 66-70. 
Felitti, V. J., Anda, R. F., Nordenberg, D., Williamson, D. F., Spitz, A. M., Edwards, V., Koss, M. P., \& Marks, J. S. (1998). Relationship of childhood abuse and household dysfunction to many of the leading causes of death in adults: The Adverse Childhood Experiences (ACE) Study. American Journal of Preventive Medicine, 14, 245-258.

Freedman, L. S., Graubard, B. I., \& Schatzkin, A. (1992). Statistical validation of intermediate endpoints for chronic diseases. Statistics in Medicine, 11, 167-178.

Gilbert, L., El-Bassel, N., Schilling, R. F., \& Friedman, E. (1997). Childhood abuse as a risk for partner abuse among women in methadone maintenance. American Journal of Drug Alcohol Abuse, 23, 581-595.

Harlow, L. L., Quina, K., Morokoff, P. J., Rose, J. S., \& Grimley, D. M. (1993). HIV risk in women: A multifaceted model. Journal of Applied Biobehavioral Research, 1(1), 3-38.

Joe, G. W., Knezek, L., Watson, D., \& Simpson, D. D. (1991). Depression and decision-making among intravenous drug users. Psychological Reports, 68(1), 339-347.

Johnsen, L. W. (1996). The relationship between sexual victimization and HIV risk behaviors and attitudes in a community sample of women: A structural equation analysis. Unpublished Doctor of Philosophy, Rhode Island, Providence.

King, M. (1986). At risk drinking among general practice attenders: Validation of the CAGE questionnaire. Psychol Med, 16, 213-217.

Leigh, B. C., \& Stall, R. (1993). Substance use and risky sexual behavior for exposure to HIV: Issues in methodology, interpretation, and prevention. American Psychologist, 48, 1035-1045.

MacDonald, T. K., Zanna, M. P., \& Fong, G. T. (1996). Why common sense goes out the window: Effects of alcohol on intentions to use condoms. Personality and Social Psychology Bulletin, 22, 763-775.

Mayfield, D., McLeod, G., \& Hall, P. (1974). The CAGE questionnaire: Validation of a new alcoholism screening instrument. American Journal of Psychiatry, 131, 1121-3.

Meilman, P. W. (1993). Alcohol-induced sexual behavior on campus. Journal of American College Health, 42(1), 27-31.

NIMH Multisite HIV Prevention Trial. (1997). Methodological overview of a multisite HIV prevention trial for populations at risk for HIV. NIMH Multisite HIV Prevention Trial. AIDS, 11(Suppl 2), S1-11.

Norris, J., \& Hughes, T. L. (1996). Alcohol consumption and female sexuality: A review. In J. M. Howard, S. E. Martin, P. D. Mail, M. E. Hilton, \& E. D. Taylor (Eds.), Women and alcohol: Issues for prevention research (Vol. 32, pp. 315-345). Bethesda, MD: U.S. Department of Health and Human Services, Public Health Service, National Institutes of Health.

Polusny, M. A., \& Follette, V. M. (1995). Long-term correlates of child sexual abuse: Theory and review of the empirical literature. Applied \& Preventive Psychology, 4 , 143-166.

SAS Software Release Version 6.12 [Computer Software]. (1997). SAS Institute Inc., Cary, NC.

Schilling, R. F., El-Bassel, N., Gilbert, L., \& Schinke, S. P. (1991). Correlates of drug use, sexual behavior, and attitudes toward safer sex among African-American and Hispanic women in methadone maintenance. The Journal of Drug Issues, 21, 685-698. 
Simons, R. L., \& Whitbeck, L. B. (1991). Sexual abuse as a precursor to prostitution and victimization among adolescent and adult homeless women. Journal of Family Issues, 12(3), 361-379.

Soet, J. E., DiIorio, C., \& Dudley, W.N. (1998). Women's self-reported condom use: Intra and interpersonal factors. Women \& Health, 4, 19-32.

Springs, F. E., \& Friedrich, W. M. (1992). Health risk behaviors and medical sequelae of childhood sexual abuse. Mayo Clinical Proceedings, 67, 527-532.

Thompson, N. J., Potter, J. S., Sanderson, C. A., \& Maibach, E. W. (1997). The relationship of sexual abuse and HIV risk behaviors among heterosexual adult female STD patients. Child Abuse \& Neglect, 21, 149-156.

Wyatt, G. E. (1988). The relationship between child sexual abuse and adolescent sexual functioning in Afro-American and White American women. Annals of the New York Academy of Sciences, 528, 111-122.

Zierler, S., Feingold, L., Laufer, D., Velentgas, P., Kantrowitz-Gordon, I., \& Mayer, K. (1991). Adult survivors of childhood sexual abuse and subsequent risk of HIV infection. American Journal of Public Health, 81, 572-575. 